\title{
A Mente NAUFRAGADA: SOBRE O ESPÍRITO REACIONÁRIO ${ }^{1}$
}

\author{
José Renato Ferraz da SILVEIRA*
}

\section{Aspectos introdutórios}

O livro A mente naufragada de Mark Lilla (2018), dedica-se ao incompreendido e pouco estudado espírito reacionário. Esse espírito moldou a imaginação de pensadores políticos e movimentos ideológicos desde o último século até os dias de hoje. Lilla afirma que é desconcertante notar que há uma infinidade de livros sobre a ideia de revolução em todas as principais línguas do mundo. Mas não temos um número adequado sobre a ideia de reação. Temos uma "presunçosa convicção de que ela se enraíza na ignorância e na intransigência, se não em motivos ainda mais inconfessáveis" (LILLA, 2018, p. 9). Podemos admitir que o pensamento reacionário é relegado "às margens da investigação intelectual respeitável” (LILLA, 2018, p. 9). Ou seja, não é merecedor de estudo e de pesquisa.

No entanto, vale ressaltar que o pensamento e o espírito reacionário são tão portentosos como o pensamento e o espírito revolucionário. O espírito reacionário que surgiu frente ao pensamento revolucionário, sobrevive e está provando ser uma força histórica igualmente impactante, seja no Oriente Médio, América Latina ou na classe média americana.

\section{Sobre o autor}

Mark Lilla é professor da Universidade de Columbia e escreve regularmente para a revista New York Review of Books e outras publicações ao redor do mundo.

\footnotetext{
UFSM - Universidade Federal de Santa Maria. Centro de Ciências Sociais e Humanas. Departamento de Economia e Relações Internacionais. Santa Maria - RS - Brasil. 97105-900 - jreferraz@hotmail.com. https://orcid.org/0000-0001-7751-7583.

1 LILLA, Mark. A mente naufragada: sobre o espírito reacionário. Trad. de Clóvis Marques. $1^{\circ}$ ed. Rio de Janeiro: Record, 2018.
} 
Autor de muitos livros, entre eles, além de A mente naufragada: sobre o espírito reacionário (2018), estão publicados em português: $A$ mente imprudente: os intelectuais na atividade política (2017), A grande separação: religião, política e $O$ ocidente moderno (2018a), De esquerda, agora e sempre: para além das políticas identitárias (2018b).

\section{Sobre a obra}

A mente naufragada de Mark Lilla é do gênero ensaístico que propõe apresentar os pensadores cuja obra estão permeadas de nostalgia moderna, correntes (dois movimentos intelectuais contemporâneos cuja retórica transita pela nostalgia) e um evento da atualidade de disposição/tendência/natureza reacionária (os mortíferos atentados terroristas cometidos por jihadistas franceses em Paris, em janeiro de 2015). Temos também um Posfácio que conclui sobre a "persistente força psicológica da nostalgia política" (LILLA, 2018, p. 18).

A obra está dividida em: Introdução (p.9-18); Pensadores (A batalha pela religião - Franz Rosenzweig, p. 21-36); (O escatón imanente - Eric Voegelin, p.37-50); (Atenas e Chicago - Leo Strauss, p. 51-66); Correntes (De Lutero ao Walmart, p. 69-82); (De Mao a São Paulo, p. 83-93); Eventos (Paris, janeiro de 2015, p. 97-114).

$\mathrm{Na}$ Introdução, Lilla infere que a palavra reação tem uma história formidável. Ela entrou no século XVIII para o vocabulário político europeu. Montesquieu (2008), na obra $O$ espírito das leis, retratava a vida política em termos dinâmicos, como uma infindável série de ações e reações. Ele identificava a revolução. Mas como um fenômeno raro e imprevisível, a Revolução Francesa mudou o significado de ambos os termos. A Revolução era vista pelos observadores como o pivô da história do mundo. Vale destacar que os Jacobinos mudaram o calendário para $o$ ano I, para demonstrar a ruptura com o passado, mudaram também o nome dos meses, para que nenhum cidadão confundisse o presente com o passado. Era o momento de emancipação humana. A pergunta que Lilla faz: como seria então a vida política? Hegel considerava que surgiriam os modernos Estados-nações burocráticos. Marx imaginou um não Estado comunista povoado por homens livres. No período jacobino, "quem quer que resistisse à correnteza do rio ou mostrasse entusiasmo insuficiente a respeito da chegada ao destino era considerado "reacionário"” (LILLA, 2018, p. 10). A palavra reacionário, a partir de então, ganhou uma conotação moral negativa que ainda hoje permanece. O formidável disso tudo foi que no século XIX é que nem todos os críticos da Revolução eram reacionários no sentido estrito. Lilla cita Benjamin Constant, Madame de Staël, Tocqueville e Edmund Burke. 
Ao citar esses autores, Lilla afirma: "os reacionários não são conservadores" (LILLA, 2018, p. 11). Os reacionários são mais parecidos com os revolucionários: tão iguais na imaginação histórica. "As expectativas milenaristas de uma nova ordem social redentora e de seres humanos rejuvenescidos inspiram os revolucionários; os reacionários são obcecados pelo medo apocalíptico de entrar numa era de escuridão". (LILLA, 2018, p. 11).

Outro ponto marcante da Introdução é relativo à nostalgia. Os reacionários contemporâneos descobriram que a nostalgia é um ingrediente motivador político, talvez mais poderoso que a esperança. "As esperanças podem ser desiludidas. A nostalgia é irrefutável" (LILLA, 2018, p. 13). O reacionário é politicamente engajado, movido por paixões, intensas emoções, suposições não menos compreensíveis que as dos revolucionários engajados, "desenvolvendo teorias não menos sofisticadas para explicar o curso da história e esclarecer o presente" (LILLA, 2018, p. 14).

Na parte dos Pensadores o autor apresenta ensaios sobre três pensadores do início do século XX em cujas obras estão presentes a nostalgia moderna - Franz Rosenzweig, Eric Voegelin e Leo Strauss.

Rosenzweig dedicou sua obra à revitalização do pensamento e prática judaicos. A nostalgia de Rosenzweig era complexa. Ele não acreditava que a volta do judaísmo à simples ortodoxia pré moderna fosse possível ou desejável. Na realidade, ele propunha um novo pensamento que fosse contrário à história e que capturasse nesse novo movimento a vital essência transcendente do judaísmo.

Voegelin, em seus longos escritos sobre religião e política, acabaria por determinar o antigo gnosticismo religioso como a força que levou o Ocidente para o desastre.

Strauss desenvolveu uma "sutil e mais profunda história da filosofia ocidental, com base em cuidadosos estudos de pensadores, indo de Platão a Nietzsche" (LILLA, 2018, p. 16). Strauss identifica Maquiavel como o autor responsável pela decisiva ruptura histórica da filosofia, passando da pura contemplação para a ação pragmática.

Na parte seguinte, Mark Lilla trata das Correntes, na qual examina dois movimentos intelectuais contemporâneos cuja retórica também transita pela nostalgia, com finalidades diferentes. Começa com o neoconservadorismo, corrente da direita americana na qual convergem católicos tradicionais, protestantes evangélicos e judeus neo-ortodoxos, apesar das diferenças doutrinárias, partilham uma categórica condenação cultural da América e de sua decadência. Culpam movimentos reformistas e a atenção está voltada aos anos 60 , como a década da ruptura na história política e religiosa americana.

O outro movimento discutido em Correntes é o intrigante movimento da extrema esquerda acadêmica que focaliza a religião sob um prisma diferente. Os 
adeptos dessa corrente lançam um olhar nostálgico para movimentos revolucionários do passado, e muitas vezes para Estados totalitários do século XX. Para eles, há profundas afinidades entre São Paulo, Lenin e Mao.

Nos Eventos, Lilla trata dos mortíferos ataques terroristas cometidos por jihadistas franceses em Paris em janeiro de 2015. Houve duas formas de reação na França. Por um lado, havia "a nostalgia dos assassinos, de baixo nível educacional, por um glorioso passado muçulmano imaginário que hoje inspira sonhos de um moderno califado de ambições globais" (LILLA, 2018, p. 17). Por outro lado, "a nostalgia de intelectuais franceses que viam no crime uma confirmação de sua visão fatalista sobre o declínio da França e a incapacidade da Europa de se afirmar diante de um desafio civilizatório" (LILLA, 2018, p. 18).

O autor finaliza a Introdução com um pensamento sobre a persistente força psicológica da nostalgia política que começa com a tragicômica tentativa de Dom Quixote de reviver uma época de Ouro.

A nostalgia política reflete uma espécie de pensamento mágico sobre a história. A vítima acredita que existiu uma Época de Ouro bem delimitada e que possui um conhecimento esotérico dos motivos de seu fim. Mas ao contrário do revolucionário moderno, cujos atos inspiram-se na crença no progresso e numa iminente emancipação, o revolucionário nostálgico não sabe ao certo como conceber o futuro e agir no presente (LILLA, 2018, p. 18).

A mente naufragada de Mark Lilla é uma excelente contribuição para entender a psicologia das nações, dos povos, das religiões e dos movimentos políticos. Obra indispensável e uma análise erudita para compreender as atuais forças sociais, econômicas e culturais, nesses tempos nebulosos e sombrios, que atingem a civilização humana.

\section{REFERÊNCIAS}

LILLA, Mark. A mente imprudente: os intelectuais na atividade política. $1^{\circ}$ ed. Rio de Janeiro: Record, 2017.

A mente naufragada: sobre o espírito reacionário. Traduzido por Clóvis Marques. $1^{a}$ ed. Rio de Janeiro: Record, 2018.

- A grande separação: religião, política e o ocidente moderno. São Paulo: Companhia das Letras, 2018a.

De esquerda, agora e sempre: para além das políticas identitárias. $1^{\text {a }}$ ed. Brasil, Tinta da China Edições, 2018. 
MONTESQUIEU, Charles de Secondat. O espírito das leis: as formas de governo, a federação, a divisão dos poderes. Introdução, tradução e notas de Pedro Vieira Mota. São Paulo: Saraiva, 2008.

Recebido em 07/06/2018.

Aprovado em 15/11/2018. 
